\title{
CISTOS ARACNÓIDEOS TEMPORAIS. RELATO DE DOIS CASOS OPERADOS
}

\author{
Gilberto Machado de Almeida* \\ JULINHO AISEN **
}

A etiologia dos cistos aracnóideos é controversa. Regli (cit. por Huber ${ }^{3}$ e por Krayenbühl e Yasargil ${ }^{5}$ ) distribuiu as causas dêstes processos em 5 grupos: 1 - perturbaçōes congênitas por malformações ou por distúrbios de posição fetal; 2 - traumatismos de parto; 3 - traumatismos após o parto; 4 - processos inflamatórios; 5 - tumores que determinam o aparecimento de cistos associados, como em alguns casos de neurinomas do ângulo pontocerebelar.

A localização mais freqüente dos cistos aracnóideos é na fossa posterior $1,2,4,6$, sendo relativamente raros os situados na região temporal ${ }^{7}$. $O$ presente trabalho baseia-se na apresentação de dois casos de cistos aracnóideos temporais, vistos com apenas um mês de intervalo.

\section{OBSERVACOES}

CASo 1 - R.C. (Reg. 751319). Criança com $2 \frac{1}{2}$ anos de idade, sexo masculino, mestiça (mãe indła e pai branco), internada em 21-12-64. Desde o parto foi notado abaulamento na região frontotemporal esquerda. Alguns meses antes da internação o doente passou a ter cefaléla. Exame fisico: macrocefalia (perimetro craniano $53 \mathrm{~cm}$ ), abaulamento frontotemporal esquerdo. Radiografias de cranio: fossa média esquerda muito aumentada (abaulamento frontotemporal, soalho do andar médio abaixado e empurrado para a frente), pequena asa do esfenóide mais alta à esquerda. Angiografía cerebral via artéria carótida esquerda: discreto desvio da artéria cerebral anterior para a direita e elevação do grupo silviano (fig. 1, A e B).

Com o diagnóstico de processo expansivo congénito na região temporal foi feita cranlectomia, em 28-12-1964. Abaixo do plano dural havia grande cisto revestido por pia-máter nas regiōes em contato com o encéfalo e por delgada membrana semelhante à aracnóide no restante. A formação cistica, que continha líquido hipertenso, límpido e incolor, ocupava a fossa média aumentada, empurrava o lobo temporal para trás e o frontal para cima. Exame histológico: aracnóide sem particularidades.

A evolução pós-operatória (9 meses) foi boa, permanecendo ligeira depressão ao nivel da craniectomia.

CASo 2 - E.F.M. (Reg. 736629). Paciente com 18 anos de idade, do sexo feminino, branca, internada em 26-1-65. Com 7 anos começou a ter dor frontotemporal direita, atingindo o arco zigomático e o ôlho direitos. A sintomatologia dolorosa tinha caráter cíclico, com periodos de acalmia de aproximadamente uma se-

Trabalho da Clínica Neurológica da Fac. Med. da Universidade de São Paulo (Prof. A. Tolosa) : * Neurocirurgião; * Residente. 

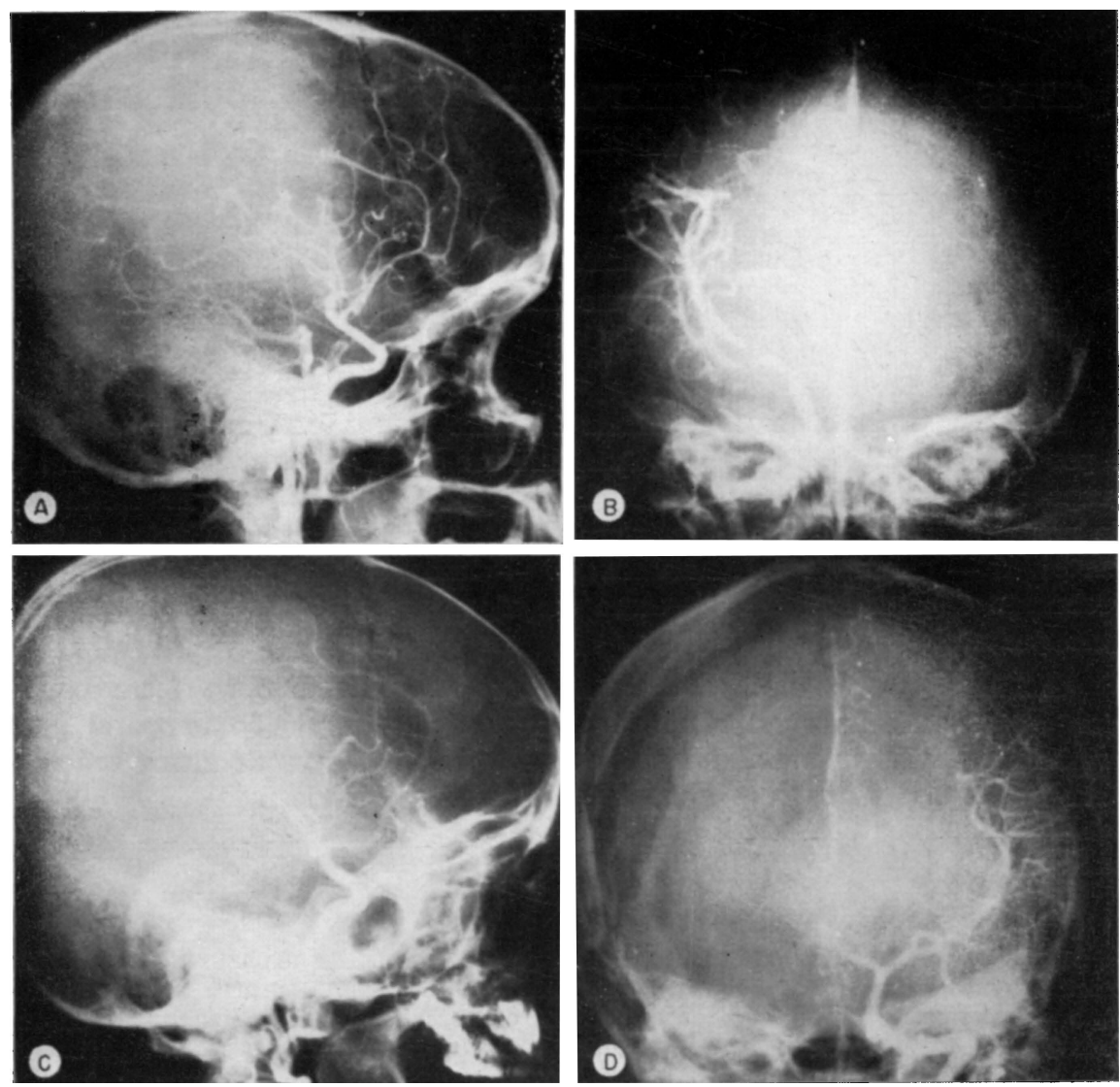

Fig. 1 - Arteriografias dos casos 1 ( $A$ e B) $e$ 2 ( $C$ e D), mostrando pequeno desvio da artéria cerebral anterior para o lado oposto e discreto deslocamento do grupo silviano para cima e para dentro.

mana. O quadro intensificou-se progressivamente e, há cêrca de 8 anos, foi notado abaulamento progressivo da fossa temporal. Ulteriormente, nas crises de dor mais intensa, ocorria escurecimento da visão; há um ano, surgiu diplopia e quadro convulsivo (crises generalizadas). Exame físico: abaulamento frontotemporal direito, doloroso à palpação; paresia do reto externo à direita; papiledema bilateral. Eletrencefalograma normal. Exame do líquido cefalorraqueano normal. Radiografias do crânio: aumento da fossa média com abaulamento frontemporal. Arteriografia cerebral via artéria carótida direita: discreto desvio da artéria cerebral anterior para a esquerda; grupo silviano elevado; veias cerebrais médias elevadas (fig. 1 , C e D).

Em 5-2-65 foi feita craniotomia temporal direita. Havia volumoso cisto na fossa média, contendo líquido hipertenso, limpido e incolor. o lobo temporal estava empurrado para trás e o frontal elevado. Das paredes da formação cística (aracnóide e pia-máter) saíam traves para o interior da cavidade. Exame histológico da membrana: aranóide pouco espessada. 
Evolução ( 7 meses) muito boa, com regressão da cefaléia, estrabismo, convulsões e papiledema.

\section{COMENTARIOS}

Em nossos casos não havia história de trauma craniano, os exames histológicos mostraram inexistência de reação inflamatória e os atos cirúrgicos afastaram a possibilidade de haver tumor. Acreditamos, portanto, que os cistos tenham decorrido de alteraçōes congênitas. As intensas deformidades ósseas, observadas no caso 1 desde o nascimento, indicam também que a instalação do processo é muito antiga. Weinman ${ }^{7}$ sugeriu que os cistos aracnóideos temporais tenham origem na canalização incompleta do espaço subaracnóideo, na época de seu desenvolvimento.

O quadro clínico caracteriza-se pelo abaulamento na região temporal, podendo, ou não, haver aumento da pressão do líquido cefalorraqueano. Weinman ${ }^{7}$ referiu que os cistos aracnóideos temporais raramente determinam quadro de hipertensão intracraniana; entretanto, além da cefaléia, encontramos macrocefalia no caso 1 e papiledema no caso 2 .

Em nosso segundo doente há referência de que o abaulamento foi notado apenas aos 10 anos de idade, mas é provável que devesse existir há muito mais tempo, não tendo sido percebido antes por causa do mascaramento provocado pelo músculo temporal e pelo zigoma.

As radiografias simples permitem verificar: abaulamento da escama temporal, elevação da asa do esfenóide, erosão da tábua interna e grande aumento da fossa média. Acreditamos que nos casos típicos apenas o quadro clínico (cronicidade, abaulamento temporal) e as radiografias simples, sejam suficientes para o diagnóstico de cisto aracnóideo temporal. Entretanto, em parte devido à relativa raridade do processo, costuma-se fazer exames neurorradiológicos para completar o estudo dêstes doentes.

Em nossos casos não foi realizada a pneumencefalografia. Huber ${ }^{3}$ afirma que o cisto não se enche de ar e refere como achados característicos dêste exame o encurtamento e o desvio para dentro do côrno temporal.

$\mathrm{O}$ aspecto arteriográfico encontrado tem sido relativamente uniforme: a artéria cerebral anterior apresenta-se na linha média ou discretamente deslocada para o outro lado e a cerebral média encontra-se desviada para cima e para dentro. Costuma-se dizer ${ }^{3,5}$ que o grupo silviano está menos elevado e estirado do que nos tumores císticos temporais. Huber ${ }^{3}$ e Krayenbühl e Yasargil ${ }^{5}$, ao discutirem o diagnóstico diferencial dos cistos aracnóideos, deram especial importância ao estudo das fases venosas, descrevendo anastomoses anômalas de veias corticais, desembocadura das veias silvianas na veia de Galeno e delimitação de terreno avascular pelas veias. Em nossos casos não pudemos confirmar tais achados a não ser no que diz respeito à área avascular.

O tratamento de tais cistos é fácil, consistindo simplesmente na abertura da membrana que o reveste. Os resultados têm sido bons nos doentes referidos na literatura, assim como nos que estamos apresentando. No caso 1 
desapareceu a cefalẻia e no caso 2 houve regressão do quadro de hipertensão intracraniana (cefaléia, paralisia do VI par, papiledema) e das convulsões.

\section{RESUMO}

Os autores apresentam dois casos de cistos aracnóideos temporais, vistos com apenas um mês de intervalo. Os dois doentes apresentavam, além do abaulamento temporal, quadro de hipertensão intracraniana que desapareceu com a operação. A etiologia do processo, nestes dois casos como na maioria dos referidos na literatura, parece estar ligada a alterações congênitas caracterizadas por canalização incompleta do espaço subaracnóideo.

\section{SUMMARY}

\section{Temporal arachnoidal cysts. Report of two cases submitted to surgery}

Two cases of patients with frontotemporal bulging caused by temporal arachnoidal cysts are reported. The cases were seen with a interval of only one month. The signs and symptoms of intracranial hypertension subsided after the surgical procedure in the two patients. In those cases the etiology of the process lies probably in congenital malformations caused by incomplete canalization of the subarachnoidal space.

\section{REFERENCIAS}

1. CHIAPPETTA, F.; CHIASSERINI, A. \& COSELlA, E. - Cisti liquorali della fossa cranica posteriore. Policlinico $71: 1697-1704,1964$. 2. HORRAX, G. - Generalized cisternal arachnoiditis simulating cerebellar tumor: its surgical treatment and end-results. Arch. Surg., 9:95-112, 1924. 3. HUBER, P. - Die neuroradiologische Differentialdiagnose der temporalen Arachnoidalzyste. Schweiz. Arch. Neurol. Neurochir. Psychiat., 89:256-275, 1962. 4. KLEIN, M. R. \& BROGLY, G. - Les kystes arachnoidiens de la fosse postérieure. Etude clinique et anatomique d'après 25 cas. Sem. Hôp. Paris 30:193-197, 1954. 5. KRAYENBUHL, H. \& YASARGIL, M. G. - Röntgenologisher Beitrag zur Diagnose zerebraler Arachnoidalzysten der Temporalregion. Schweiz. Arch. Neurol. Neurochir. Psychiat., 89:327-339, 1962. 6. LFWIS, A. J. - Infantile hydrocephalus caused by arachnoid cyst. J. Neurosurg., 19: 431-434, 1962. 7. WEINMAN, D. F. - Arachnoidal cysts in the sylvian fissure of the brain. J. Neurosurg., 22:185-187, 1965.

Clínica Neurológica - Faculdade de Medicina da Universidade de Säo Paulo - Caixa Postal $\$ 461$ - São Paulo, SP - Brasil. 